\title{
A POLÍTICA EDUCACIONAL DO CURSO DE DIREITO E PROCESSO DE AVALIAÇÃO DO EXAME DA OAB
}

\author{
THE EDUCATIONAL POLICY OF THE COURSE OF RIGHT AND PROCESS OF \\ EVALUATION OF THE OAB EXAM
} \\ RAPHAEL SWERTS \\ Centro Universitário UNA, Brasil \\ CLÁUDIO M. MAGALHÃES ${ }^{2}$ \\ Centro Universitário UNA, Brasil
}

RESUMO: O presente trabalho possui o objetivo de analisar a política educacional ofertada nos cursos de direito no Brasil, uma vez que existe um alto índice de reprovação no processo avaliativo do Exame da Ordem dos Advogados do Brasil. Neste sentido, buscou-se entender que tipo de educação é aplicada no ensino jurídico superior, bem como sua metodologia, além de fazer um recorte sobre as políticas que estão sendo discutidas sobre o tema. Foi utilizada pesquisa bibliográfica para elucidar tais questionamentos. Como resultado, além de uma proposta de abordagem crítica sobre o estado da arte da educação do Direito e suas metas pedagógicas, foram feitas propostas de como pensar alternativas aos problemas levantados, como a discussão sobre o 'paralegal' e suas potencialidades como agente social.

PALAVRAS-CHAVE: Bacharel em direito; educação; processo avaliativo da OAB.

\begin{abstract}
The present work has the objective of analyzing the educational policy offered in law courses in Brazil, since there is a high rate of disapproval in the evaluation process of the Examination of the Brazilian Bar Association. In this sense, we sought to understand what kind of education is applied in higher legal education, as well as its methodology, as well as to make a clipping about the policies that are being discussed on the topic. Bibliographic research was used to elucidate such questions. As a result, besides a proposal of a critical approach on the state of the art of Law education and its pedagogical goals, proposals of how to think alternatives to the problems raised, such as the discussion about the 'paralegal' and its potential as a social agent.
\end{abstract}

KEYWORDS: Bachelor in right; education; OAB assessment process.

\footnotetext{
${ }^{1}$ Advogado inscrito na OAB/MG, Professor Universitário, Mestre em Gestão Social, Educação e Desenvolvimento Local pelo Centro Universitário UNA, Pós-Graduado em Direito Civil Aplicado pela PUC/MG, Bacharel em Direito pela Escola Superior Dom Helder Câmara. Contato: raphaelswerts@ gmail.com

${ }^{2}$ Professor/Orientador do Programa de Pós-graduação em Gestão Social, Educação e Desenvolvimento Local e do Instituto de Comunicação e Artes do Centro Universitário UNA, Doutorado em Educação e Mestrado em Comunicação Social pela UFMG. Contato: claudiomagalhaes@uol.com.br
} 


\section{INTRODUÇÃO}

No presente trabalho será apresentado os contornos do conceito de educação, bem como a discussão sobre a aplicação do modelo da política educacional no curso de Direito no Brasil, com o intuito de situar a discussão tanto em relação à sua problemática quanto ao seu potencial teórico e prático. Será abordado os detalhes do conceito então discutido, passando à exposição e à análise de seu processo educacional superior, confrontando com o alto índice de reprovação na avaliação de proficiência da Ordem dos Advogados do Brasil, além de perpassar pela reflexão da utilização das políticas que estão sendo discutidas sobre a situação Bacharel em Direito, para tentar explicar a possibilidade e real atribuição sobre o papel desempenhado do operador em direito na sociedade.

\section{EDUCAÇÃO E SEUS TIPOS: FORMAL, NÃO FORMAL, INFORMAL}

A definição de educação adotada neste estudo leva em consideração as dimensões cognitiva, afetiva e psicomotora, como explicado por Costa (2014), citando Belle (1976):

Utilizarei, portanto, uma definição de educação que por hora servirá para as finalidades deste estudo bibliográfico. Thomas J. La Belle (1976, p. 18) a caracteriza como um processo através do qual indivíduos aprendem como agir cognitiva, afetiva e psicomotoramente dentro de seus ambientes, podendo ser fruto de direcionamentos externos ou da iniciativa pessoal do próprio indivíduo (COSTA, 2014, p. 437).

A categorização da educação dá-se em três gêneros - formal, não formal e informalentendendo-a como um aprendizado contínuo:

Coombs, Prosser e Ahmed (1973) foram alguns dos pioneiros em categorizar o conceito de educação em três diferentes tipos - informal, formal e não formal -, examinando sistematicamente cada um deles. Na visão destes autores, a educação é tida como um processo de natureza contínua, que acompanha o indivíduo desde os seus primeiros passos até a mais distante vida adulta, envolvendo uma diversidade significativa de métodos e recursos de aprendizagem (p. 9-10) (COSTA, 2014, p. 437).

Soma-se à discussão a percepção mais abrangente trazida por Gaspar (2002):

A educação, entendida como um processo de desenvolvimento da capacidade intelectual da criança e do ser humano, tem um significado tão amplo e abrangente que, em geral, prescinde de adjetivos. É um processo único, associado quase sempre à escola (GASPAR, 2002, p. 171).

Os adjetivos mencionados pelo autor acabam por se tornarem uma referência e desmembram-se nas modalidades ou possibilidades de educação disponíveis atualmente, o que pode ser aplicado ao ensino superior. Para Gaspar (2002), na educação informal:

Não há lugar, horários ou currículos. Os conhecimentos são partilhados em 
meio a uma interação sociocultural que tem, como única condição necessária e suficiente, existir quem saiba e quem queira ou precise saber. Nela, ensino e aprendizagem ocorrem espontaneamente, sem que, na maioria das vezes, os próprios participantes do processo deles tenham consciência (GASPAR, 2002, p. 173).

A educação informal, em outras palavras, é aquela realizada por meio do convívio social, familiar, dentre outros, na qual o receptor se coloca à disposição para adquirir tais habilidades no dia a dia por meio de suas experiências pessoais de convivência.

Já a educação denominada de não formal é derivada da educação formal, não podendo, entretanto, se confundir, já que a educação não formal é autônoma.

A educação não-formal para Costa (2014):

Por educação não-formal Coombs, Prosser e Ahmed (1973) entendem quaisquer atividades educacionais organizadas e sistematizadas que ocorram fora do sistema formal estabelecido, ainda que operem em consonância ou de maneira complementar ao último. Tais atividades são pensadas e desenhadas para atender um grupo específico, com objetivos de aprendizado bem delineados. Muitos dos processos educacionais pensados pelos autores como pertencentes à categoria "não-formal" não foram sequer originalmente concebidos como sendo educacionais. Grande parte deles foi pensada como atividades de lazer e de esporte, serviços de saúde, projetos de desenvolvimento de comunidades e regiões específicas, entre outros. Sendo assim, a educação não-formal abarcaria "componentes educacionais de programas projetados para atenderem a metas de desenvolvimento amplas, bem como a objetivos mais acadêmicos7" (COOMBS, PROSSER E AHMED, 1973, p. 12 apud COSTA, 2014, p. 438).

Para melhor ilustração da educação não formal, em tempos atuais, a mesma encontra-se muito presente com o advento da internet e seus sites de vídeos, possibilitando a qualquer pessoa usufruir de uma atividade educacional sistemática, organizada, sem necessariamente compor um ambiente literal de sala de aula.

Desta forma, tem-se o entendimento de educação formal, e como o próprio nome já diz, carrega sua “formalidade' na metodologia de ensino, como explicado por Costa (2014):

Para Moacir Gadotti (2005, p. 2), a educação formal possui objetivos e meios claramente definidos e tem como local de ocorrência principal, o ambiente escolar. Ela responde a uma gerência normalmente centralizada e que se organiza através de uma estrutura hierárquica, burocrática, que atua em nível nacional. Tal estrutura faz-se percebida através dos currículos e dos órgãos fiscalizadores do Ministério da Educação. Segundo ele, e aqui opondo-se ao entendimento do conceito de educação não-formal tal qual entendido por Paulston (1972, citado por LA BELLE, 1976, p. 21), esta pode ocorrer através de processos de duração variável, a depender da necessidade, disponibilidade de recursos, intenção e outros fatores relacionados aos envolvidos dentro de um processo educativo de tal natureza (COSTA, 2014, p. 440).

Lado outro temos Gaspar (2002) que de forma mais sucinta explica:

A educação com reconhecimento oficial, oferecida nas escolas em cursos com níveis, graus, programas, currículos e diplomas, costuma ser chamada de educação formal. É uma instituição muito antiga, cuja origem está ligada ao desenvolvimento de nossa civilização e ao acervo de conhecimentos por ela 
gerados (GASPAR, 2002, p 171).

Em linhas gerais, a educação formal refere-se à tradicional, ou seja, o tipo de educação mais comum, que todos conhecem, pautada em metodologias de programas pedagógicos, sala de aula, notas, níveis, graus, currículos e diplomas, as mesmas utilizadas no Japão, por exemplo, como destaca Kanayama, Filho e Tomio (2014).

As instituições de ensino superior no Brasil utilizam essa última modalidade para seus ciclos de aprendizagem no ambiente acadêmico. O próximo tópico abordará melhor essa questão, tendo como ênfase o curso de Direito no Brasil.

\title{
3 EDUCAÇÃO NO CURSO DE DIREITO NO BRASIL
}

Para entender a política educacional no Curso de Direito, é necessário analisar como se dividem as disciplinas da grade curricular. Elas se organizam por meio de duas variantes. A primeira divisão da grade curricular tem o olhar da zetética, que é voltada para resolução de problemas teóricos; já a segunda, por sua vez, é denominada de disciplinas dogmáticas, fixadas e ligadas aos conceitos já estipulados do curso em si (ALMEIDA, SOUZA E CAMARGO, 2013).

Os autores ainda trazem de forma mais cristalina as disciplinas em debate, como mencionam:

\begin{abstract}
Zetéticas são, por exemplo, as investigações que têm como objeto o direito no âmbito da Sociologia, da Antropologia, da Psicologia, da História, da Filosofia, da Ciência Política etc. Essas disciplinas servem não só para informar os juristas, mas, principalmente, para formá-los. Por sua vez, dogmáticas são definidas à medida que consideram certas premissas, em si e por si arbitrárias, como vinculantes para o estudo, renunciando-se, assim, ao postulado da pesquisa independente. Ao contrário das disciplinas zetéticas, cujas questões são infinitas, as dogmáticas tratam de questões finitas (ALMEIDA, SOUZA E CAMARGO, 2013, p. 19).
\end{abstract}

Em outras palavras, conforme já dito, o pilar das disciplinas zetéticas busca formar pensadores/pesquisadores ou oportunidades para pensar em algo fora do óbvio. Todavia, as disciplinas dogmáticas no curso de Direito passam pelo Direito Penal, Direito Civil, Direito Constitucional, Direito do Trabalho, entre outras. Todas essas, acorrentadas aos seus códigos, dificultam o pensamento fora do dispositivo legal já definido pelo Legislador.

O ensino jurídico atual vem enfrentando dificuldades nos últimos tempos, pois, tem falhado ao tentar andar junto com as mudanças sociológicas, políticas, educacionais e econômicas no cotidiano do Brasil (ALMEIDA, SOUZA E CAMARGO, 2013).

Ocorre que as instituições de ensino de curso de Direito esbarram no tradicionalismo que é passado de tempos em tempos. Elas fornecem um ensino jurídico totalmente legalista e 
rebuscado de suas formalidades, deixando de lado mecanismos didáticos para entender a real necessidade social, colocando um abismo entre a aplicação do direito de forma legal e a verdadeira necessidade social (ALMEIDA, SOUZA E CAMARGO, 2013).

O que acontece, de fato, é um certo desprezo no cotidiano das academias jurídicas sobre as disciplinas zetéticas, que ajudam a entender a realidade e o posicionamento real em que a sociedade se encontra, priorizando um sistema dogmático, que fortalece a lógica do discente não pensar o direito, mas sim repetir o Direito. Neste contexto, pertinente se faz as palavras de Frederico Almeida:

No ensino jurídico isso se traduz quando aprendemos artigo por artigo de leis, de vários ramos do Direito, sendo que uma parte dessas normas já está ou estará em descompasso com a realidade social quando nos formamos. Mais do que isso, a própria organização de cursos dogmáticos baseados na estrutura e na pretensão de esgotamento de leis e grandes códigos reforça esse aspecto, claramente limitado, do ensino jurídico. Com esse dogmatismo, os cursos jurídicos têm formado profissionais incapazes de perceber a dimensão real dos problemas com os quais terão de lidar (ALMEIDA, SOUZA E CAMARGO, 2013, p. 21).

Neste diapasão, as academias de Direito são desafiadas a levar seus discentes a saírem da "caixa" que os aquartela, deixando de lado por alguns momentos o ensino jurídico dogmático e se aventurarem na zona zetética.

O exercício de enxergar o direito sob outra ótica, na perspectiva dos alunos, favorece novas formas de avaliar as experiências para o mercado de trabalho, permitindo àqueles o desenvolvimento de suas atividades com mais firmeza e sagacidade, a partir da multidisciplinariedade no Direito (ALMEIDA, SOUZA E CAMARGO, 2013).

Os autores destacam que a interação com a realidade faz-se necessária ao acompanhamento das disciplinas zetéticas, ministradas no Curso de Direito, utilizando em conjunto o aprendizado das disciplinas dogmáticas, de modo que os alunos do curso de Direito possam atingir maturidade acadêmica a partir da equidade dos conhecimentos basilares, conjugada à realidade social.

Ao mesmo tempo, compreendendo que o ensino jurídico não se faz somente com a leitura das doutrinas e códigos de Direito, bem como o modelo de aulas expositivas tradicionais expostas cotidianamente em sala de aula; pelo contrário, ao adquirir um olhar diferenciado, os estudantes passam a ser operadores do Direito que dialogam com a formalidade do Direito e a realidade na qual vivem.

Leister e Trevisam (2013) questionam se os bacharéis em Direito, após terem assistido o conteúdo das disciplinas zetéticas e dogmáticas, estão de fato prontos para os desafios impostos às suas carreiras. Ademais, com a evolução social em constante transformação, seriam capazes 
de encarar as mudanças para ajudarem o desenvolvimento da sociedade?

A tendência de a resposta ser negativa é maior pois, segundo as autoras, o problema na educação no curso de Direito no Brasil está bem além de uma simples discussão sobre qual enfoque de disciplinas utilizar.

Com o real avanço do número de escolas de Direito, Mello (2011) e Kanayama, Filho e Tomio (2014) destacam que há uma concorrência forte para a obtenção e a permanência dos estudantes, o que coloca as instituições de ensino propensas a darem ênfase mais no mercado do que na qualidade acadêmica.

Neste diapasão, a reprodução das instituições de ensino superior em massa traz um desfavor para a sociedade e seu desenvolvimento local, uma vez que a formação se tornará banalizada, produzindo profissionais de baixa qualidade (LEISTER E TREVISAM, 2013):

Essa ampliação se apresentou com um aumento considerável dos cursos superiores em todo o país, principalmente com a proliferação de faculdades particulares sem o mínimo de estrutura educacional, que, no afã de alcançar um maior poder econômico, não estão preocupadas com a qualidade de ensino. Trata-se de um problema cada vez mais complexo e com poucas alternativas de solução. A educação no Brasil, de fato, encontra-se totalmente relegada ao segundo plano, não havendo nela qualquer compromisso com a qualidade. Proliferam instituições de ensino, como se o desenvolvimento do conhecimento estivesse atrelado ao número de estabelecimentos criados. Preocupa-se com a quantidade, sem compromisso com a missão maior de educar cidadãos para o futuro (LEISTER E TREVISAM, 2013, p. 48).

Como as prioridades das instituições de ensino jurídico têm sido questionadas, o medidor de eficiência dos bacharéis em Direito também muda. Aqui talvez esteja a resposta para a ênfase nas disciplinas dogmáticas dando menor importância às zetéticas, uma vez que a carreira do bacharel em Direito se desdobra em algum tipo de concurso, nos moldes de processos avaliativos de questões objetivas, subjetivas e em alguns casos até orais.

Segundo Leister e Trevisam (2013) tem sido colocada uma barreira pelos gestores da educação no curso de Direito no Brasil ao dificultarem, de forma velada, a utilização da interdisciplinaridade, isto é, reforçam a utilização dos conceitos fechados dogmáticos do curso de Direito. O problema disso é não se importar com a realidade vivenciada pelos seus discentes, sem analisar ou projetar o cruel mercado de trabalho em que serão despejados.

Ocorre que o olhar das instituições de ensino jurídico no Brasil se perfaz no empenho de obter o maior número de bacharéis possíveis aprovados em concursos públicos e, principalmente, no processo avaliativo da Ordem dos Advogados do Brasil. Exame este que é o caminho mais natural de vários bacharéis em Direito para obterem a regular inscrição nos quadros da Ordem dos Advogados do Brasil (OAB) e poderem se inserir no mercado de trabalho como advogados.

Por isso, a insistência e o olhar da educação jurídica no Brasil não saem das disciplinas 
dogmáticas, pois ali está a base "necessária" para o futuro bacharel em Direito passar nas provas de concursos públicos.

Por outro lado, nada se faz com a realidade que o bacharel em Direito vai enfrentar de fato em suas atribuições que estão, segundo Leister e Trevisam (2013), além das petições, audiências e cartórios, pois, a preocupação com o lado social e com a sociedade de fato são atributos do operador do Direito.

Desta maneira, os discentes que se formam são treinados somente para olharem para lado "automático" e cotidiano do Direito, isto é, analisar a letra fria da lei, e não atuarem em conjunto com a ótica das disciplinas zetéticas (LEISTER E TREVISAM, 2013).

A educação jurídica clama por diretrizes curriculares com uma nova configuração, fundamentada e voltada para uma formação ética preocupada com a efetiva construção da cidadania e preocupada com o desenvolvimento da sociedade e que ultrapasse o pensamento tradicionalista fundado no positivismo e literalmente dogmatizado, para conseguir, desse modo, concretizar a aplicação plena da Justiça. Não se pode admitir que os profissionais do Direito, cuja missão maior é proteger e defender a própria liberdade de cada um dos membros da sociedade, estejam mal preparados, pois, em assim sendo, estar-seá colocando em jogo princípios muito caros para a humanidade, princípios esses conquistados a duras penas e que formam a própria essência da pessoa, ligados ao Estado Democrático de Direito, à soberania, à segurança jurídica (LEISTER E TREVISAM, 2013, p. 67).

Zugman e Bastos (2013) reforçam a ideia de que o ensino jurídico no Brasil está pautado nas aprovações dos alunos em concursos bem como no processo avaliativo do Exame de Ordem. Para eles, os futuros bacharéis são treinados de modo massificado para o método de ensino de repetição. Isto é, os professores replicam o texto legal, replicam os moldes das questões que são cobradas nos concursos públicos e na prova avaliativa da $\mathrm{OAB}$ nacional e basta que os alunos sejam capazes de guardarem essas diretrizes para lograrem êxito após a formatura.

No mesmo sentido, Freire (1987), em sua obra "Pedagogia do Oprimido", denomina essa maneira de educar como "concepção bancária da educação", e diz:

Em lugar de comunicar-se, o educador faz "comunicados" e depósitos que os educandos, meras incidências, recebem pacientemente, memorizam e repetem. Eis aí a concepção "bancária" da educação, em que a única margem de ação que se oferece aos educandos é a de receberem os depósitos, guardá-los e arquiválos. Margem para serem colecionadores ou fichadores das coisas que arquivam. No fundo, porém, os grandes arquivados são os homens, nesta (na melhor das hipóteses) equivocada concepção "bancária" da educação. Arquivados, porque, fora da busca, fora da práxis, os homens não podem ser. Educador e educandos se arquivam na medida em que, nesta distorcida visão da educação, não há criatividade, não há transformação, não há saber. Só existe saber na invenção, na reinvenção, na busca inquieta, impaciente, permanente, que os homens fazem no mundo, com o mundo e com os outros. Busca esperançosa também (FREIRE, 1987, p.33,).

Assim, segundo Zugman e Bastos (2013), essa política metodológica respaldada pelas 
disciplinas dogmáticas do curso de Direito garante aos bacharéis a presença ou a chancela para efetuarem concursos públicos e/ou enfrentarem o processo de avaliação para se tornar Advogados, e obter sua inscrição profissional nos quadros da OAB. Esses dois métodos de concurso, sujeitam-se à metodologia de repetição e memorização das disciplinas dogmáticas do curso de Direito. Desta forma, os autores asseguram que:

A função certificatória dos cursos de direito também pode ser explicada pela dinâmica do mercado jurídico hodierno. Em uma dimensão maior, replicam-se as relações ocorridas no processo de avaliação dos discentes, acima descritas. Nessa medida, às instituições de ensino cabe apenas certificar os alunos capazes de replicar as informações transmitidas pelos professores. Esse certificado permite a participação em concursos públicos e na advocacia, mediante aprovação no exame da $\mathrm{OAB}$, ambos seguindo o modelo de memorização e reprodução de informação e não de construção do conhecimento. Ou seja, a realidade além dos muros da universidade também é pautada pela prevalência do produto sobre o processo (ZUGMAN E BASTOS, 2013, p. 113-114).

Corroborando para tal, Esteban (2013) afirma que o cenário do fracasso escolar em qualquer fase, é fruto de uma mensagem homogênea que liga diretamente o protocolo da política de aprendizagem dos sujeitos pela prática, tendo em vista um processo de resultados. O problema está instaurado, pois segundo pesquisa realizada em outubro de 2016 pelo Ministério da Educação e Cultura (MEC) existem, hoje no Brasil, mais de 1000 faculdades de Direito ativas (BRASIL, 2016). O cenário ainda se agrava, uma vez que a maior parte dos bacharéis em Direito, mesmo seguindo a metodologia de repetição, não logram êxito nos concursos públicos e nem no processo avalição do Exame de Ordem. Ao se atentar exclusivamente para as avaliações da $\mathrm{OAB}$, pode-se observar o alto índice de reprovação. Desde a unificação nacional do exame em 2010 até 2016 tem-se que, da totalidade de inscritos para a prova, aproximadamente $79 \%$ dos mesmos foram reprovados, como mostra a Tabela 01 .

Processo avaliativo da OAB (2010-2016)

\section{$\mathbf{N}^{0}$ Inscritos $\mathbf{N}^{0}$ Aprovados $\quad \mathbf{N}^{0}$ Reprovados}

\begin{tabular}{lccc}
\hline I Exame de Ordem Unificado & 95.844 & 13.339 & 82.505 \\
II Exame de Ordem Unificado & 107.029 & 15.720 & 91.309 \\
III Exame de Ordem Unificado & 106.891 & 12.534 & 94,307 \\
IV Exame de Ordem Unificado & 121.308 & 18.223 & 103.085 \\
V Exame de Ordem Unificado & 108.335 & 26.010 & 82.325 \\
VI Exame de Ordem Unificado & 101.932 & 25.912 & 76.020 \\
VII Exame de Ordem Unificado & 111.927 & 16.419 & 95.508 \\
VIII Exame de Ordem Unificado & 117.884 & 20.767 & 97.117
\end{tabular}




\section{Processo avaliativo da OAB}

(2010-2016)

\section{$\mathbf{N}^{0}$ Inscritos $\mathbf{N}^{\mathbf{0}}$ Aprovados $\quad \mathbf{N}^{0}$ Reprovados}

\begin{tabular}{|c|c|c|c|}
\hline IX Exame de Ordem Unificado & 118.562 & 13.151 & 105.411 \\
\hline X Exame de Ordem Unificado & 124.914 & 33.954 & 90.960 \\
\hline XI Exame de Ordem Unificado & 101.194 & 13.885 & 87.309 \\
\hline XII Exame de Ordem Unificado & 128.056 & 16.662 & 111.394 \\
\hline XIII Exame de Ordem Unificado & 123.183 & 18.465 & 104.718 \\
\hline XIV Exame de Ordem Unificado & 110.829 & 19.364 & 91.465 \\
\hline XV Exame de Ordem Unificado & 111.816 & 23.546 & 88.270 \\
\hline XVI Exame de Ordem Unificado & 112.580 & 17.807 & 94.773 \\
\hline XVII Exame de Ordem Unificado & 133.394 & 33.738 & 99.656 \\
\hline XVIII Exame de Ordem Unificado & 120.251 & 18.911 & 101.340 \\
\hline XIX Exame de Ordem Unificado & 134.618 & 15.132 & 119.486 \\
\hline
\end{tabular}

Tabela 01: Resultado geral do processo avaliativo do Exame de Ordem Unificado do Brasil entre o período de 2010 a $2016^{3}$

Fonte: Relatórios de desempenho por IES e Campus da Ordem dos Advogados do Brasil, 2016, retirados do site <http://www.oab.org.br/servicos/examedeordem> (acesso em 18/10/2016). Elaboração própria.

Com os altos índices de reprovação, novos dilemas circundam essa classe acadêmica. $\mathrm{O}$ que fazer com mais de um milhão de bacharéis que não conseguem lograr êxito no processo avaliativo do Exame de Ordem? A oferta de concursos suprirá a demanda desse público? Qual o índice de absorção desses formandos pelo mercado de trabalho? Qual o grau de desvio funcional dos mesmos, tendo em vista sua formação acadêmica comparada à sua efetiva ocupação profissional no mercado? Todo bacharel em Direito precisa necessariamente seguir a advocacia ou a carreira pública?

Para Almeida, Souza e Camargo (2013), um dos caminhos seria criar políticas públicas para conferir a esse bacharel papeis, hoje restritos à prática privativa da advocacia, resguardada pela Lei 8.906/94 - Estatuto da Ordem, como as funções de conciliação, mediação e arbitragem (ALMEIDA, SOUZA E CAMARGO, 2013)

Por fim, os cursos de Direito deveriam se inserir no esforço institucional e

${ }^{3}$ O período do recorte analisado é até 2016 , pois a partir de então a OAB começou a utilizar uma ferramenta de repescagem do aluno que é reprovado na segunda etapa podendo fazer a seguinte sem a necessidade de fazer a primeira etapa novamente. Sendo assim, os números não são exatos após 2016. 


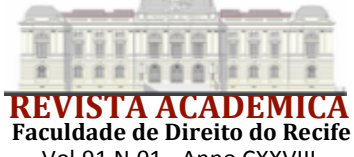

Vol 91 N.01-Anno CXXVIII

político, demonstrado pela sociedade civil e pelo próprio Poder Judiciário (Secretaria de Reforma do Judiciário, 2005), de descongestionar o Poder Judiciário com a utilização dos outros meios de solução de conflito (conciliação, mediação e arbitragem). Como essas outras formas de resolução de lides têm uma visão especializada e singular de determinados problemas, e muitas vezes contam com a intervenção de outros profissionais fora da área do Direito (psicólogos, líderes comunitários, assistentes sociais), podem fornecer outro tipo de aprendizado para os estudantes, estimulando, na prática, uma verdadeira interdisciplinaridade. Além disso, tais atividades encontram-se fora do arco de atividades consideradas privativas da advocacia; por isso, tornariam possível aos cursos jurídicos estruturarem núcleos de práticas jurídicas mais diversificados, tanto em termos de práticas realizadas como em termos de perfil da demanda atendida (ALMEIDA, SOUZA E CAMARGO, 2013, p. 25-26).

Seguindo esse conceito, o bacharel em Direito poderia ser aproveitado como operador do Direito na função que se formou, de forma legal, ajudando assim a garantir o desenvolvimento local e social, por meio da aplicação do seu conhecimento acerca das disciplinas zetéticas.

\section{A DISCUSSÃO POLÍTICA SOBRE O TEMA}

A partir do exposto no tópico anterior, surgem novas indagações: $\mathrm{O}$ que fazer com esse contingente altíssimo de bacharéis em Direito que não se encontra no mercado de trabalho? Como criar políticas educacionais para aproveitar profissionalmente o conhecimento adquirido durante cinco anos por estes estudantes do Direito de forma legal? Certo é que, esses processos de avaliação da OAB, interfere no cotidiano dos bacharéis, deixando milhares deles desempregados, sem poderem exercer profissionalmente o conhecimento adquirido na academia.

Para quebrar o paradigma enraizado no cotidiano doa bacharéis em Direito, Cowley (2004) e Brittain e Hull (2003) ressaltam que a atividade dos autores de "Assistente Legal”, é instituída nos Estados Unidos da América há décadas. Os autores ainda justificam a utilização dessa modalidade de emprego, assegurando que existe uma economia nos cofres públicos com a diminuição de ações judiciais, as quais são solucionadas extrajudicialmente pelos também chamados de Paralegais o que, por sua vez, contribui para o aumento da produtividade, qualidade e eficiência das práticas legais, pois o profissional pode ser utilizado em matérias de pequenas causas, tais como elaboração de contrato, mediação, etc.

Observando sua aplicabilidade no Brasil, entende-se que essa prática poderia ser uma solução para as dezenas de milhares de bacharéis em Direito existentes no país; se não fosse a política de restrição da $\mathrm{OAB}$ no ordenamento jurídico brasileiro, que condiciona as atividades desempenhadas pelo Paralegal nos EUA ao exercício privativo da advocacia (conforme artigo $1^{\circ}$ da Lei 8.906/94). 


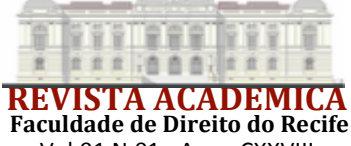

do Recife

O que se tem até o momento como discussão de políticas públicas educacionais sobre a temática, é um Projeto de Lei, nº 5.749 de 2013, de autoria do Deputado Federal Sérgio Zveiter, que dispõe sobre a criação da figura do Paralegal aqui no Brasil (BRASIL, 2013).

A sua justificativa corrobora para este debate, na medida em que Zveiter (BRASIL, 2013) reconhece que o crescente número de bacharéis em Direito, fora do mercado de trabalho, acarreta um desastre social. Isso se dá pelo fato deles não poderem exercer legitimamente os ensinamentos adquiridos na academia de Direito e, por isso, encontram-se em um caminho obscuro. Ademais, essa PL 5.749/13 pode ser o remédio que urge para preservar a dignidade da pessoa humana no convívio social, extraindo do esquecimento esses profissionais sem profissão.

De acordo com Zveiter (BRASIL, 2013), as faculdades também possuem responsabilidade na geração desse fato social, por não entregarem o conhecimento básico para o acadêmico. Para o Deputado, uma possível solução seria a criação de uma outra função para o bacharel em Direito, dando a ele uma atribuição de auxiliar da justiça nas demandas jurídicas em que não fizesse necessário a presença de um advogado. Tal função é quase uma cópia do modelo aplicado nos Estados Unidos da América, a partir da figura do Paralegal.

Segundo o andamento processual da PL, extraído do site da Câmara dos Deputados, mostra que o Projeto de Lei 5.749/13 foi devidamente aprovado pela Comissão de Constituição e Justiça e Cidadania - CCJC, no dia 06/08/2016 (BRASIL, 2013), o que seria uma vitória e a possível solução para a profissionalização dos bacharéis em Direito.

Todavia, o texto original assegurava prazo indeterminado para a nova profissão jurídica, isto é, o então Paralegal atuaria o tempo que fosse necessário e perderia o direito somente quando, e se quisesse, se inscrever como advogado após o preenchimento dos requisitos legais para tal.

Ocorre que, conforme o andamento do processo da PL em debate, o Deputado Federal Fábio Trad solicitou uma mudança nesse sentido. Segundo ele a alteração seria no novo artigo $9^{\circ}$-B, $\S 2^{\circ}$, onde no lugar da palavra indeterminado, passaria a ser, prazo máximo de três anos, o que foi acolhido pela CCJC.

Se isso ocorrer, de nada adianta toda a justificativa elencada acima do PL no 5.749/13, pois, após três anos inseridos pela nova redação do Projeto, os bacharéis em Direito fatalmente voltariam para o limbo profissional citado por Zveiter (BRASIL, 2013), fortalecendo a política de restrição da $\mathrm{OAB}$.

Kanayama, Filho e Tomio (2014) aduzem que é prejudicial ao país a grande gama de cursos jurídicos ativos pois, segundo ele, a maioria destes não propiciam uma educação de qualidade mínima. 
Dessa forma, sustentam Kanayama, Filho e Tomio (2014) que o reconhecimento e a legalização a qualquer preço do Paralegal no Brasil como pretende a PL de Zveiter (BRASIL, 2013) é confirmar o sepultamento da educação jurídica no Brasil. Para os autores, deve-se primeiramente, antes de permitir que bacharéis sejam profissionalizados a toque de caixa, promover uma discussão de novas formas de políticas públicas para guiar os caminhos futuros da educação brasileira, educação superior e não menos importante a educação jurídica no Brasil.

Kanayama, Filho e Tomio (2014) alegam que o momento do cenário acadêmico atual urge por uma reforma da educação, principalmente no ensino jurídico. Na mesma assentada, iniciar os debates sobre a adoção ou não dos Paralegais, uma vez que o que está em jogo não é só a educação em seu todo, mas sim a segurança jurídica da sociedade democrática brasileira.

\section{CONCLUSÃO}

Nessa ótica, a educação formal aplicada ao ensino superior jurídico tem que ser tratada de maneira mais séria, pois como abordado, este tipo de educação se aprisiona no próprio nome, ou seja, a educação mais tradicional possível, carregada de suas metodologias de sala de aula e notas. Este método das políticas educacionais que são utilizado nas escolas de ensino superior no Brasil e, principalmente, nos cursos de Direito.

Assim, a educação formal no curso de Direito no Brasil, se baseia em duas variantes. De um lado as Disciplinas Zetéticas que são voltadas para a resolução de problemas teóricos, e a outra as Dogmáticas, ancoradas nos conceitos profissionais do curso.

Este cenário é comprovado pelo próprio site da OAB Nacional, ferramenta de transparência do processo avaliativo da Ordem dos Advogados do Brasil, o qual informa que, segundo os números apontados e transcritos pela tabela 1, existe uma taxa de reprovação entre os anos de 2010 a 2016 de cerca de 1.722 .745 candidatos.

Entretanto, enquanto os cursos jurídicos não se amoldam aos novos tempos, deixando para trás as metodologias formais tradicionais levantadas, uma grande parte desses bacharéis que estão no limbo profissional passarão pela experiência de depreciação da qualidade de vida.

Neste sentido a corrida desenfreada aos cursos de Direito não acarreta benefício para a sociedade e seu desenvolvimento local, uma vez que a formação acadêmica torna-se precária passando por um fracasso escolar, por terem candidatos não aptos a cursarem Direito, despejando no mercado profissionais de qualidade duvidosa.

Desta forma, com a qualidade do ensino ficando baixa, não resta outro medidor de eficiência profissional para os bacharéis em Direito, além do temido processo avaliativo do 
Exame de Ordem nacional. Em outras palavras, as instituições de ensino jurídico possuem um foco em aprovar o máximo de alunos em cada etapa das avaliações da $\mathrm{OAB}$, bem como em concursos públicos para que esse resultado seja revertido em propaganda da instituição para obter mais alunos.

Desta feita, é necessário que sejam elaboradas, no Brasil, políticas públicas como a de tentativa do Deputado Zveiter (BRASIL, 2013) para poder sanar esse impasse social, atribuindo um processo de profissionalização do bacharel em Direito como Paralegal.

Se isso ocorrer futuramente, haja vista que a PL está já em vias de ser votada em plenário, os órgãos governamentais, bem como a Ordem dos Advogados do Brasil poderiam utilizar como referência as experiências internacionais já aqui aludidas como, por exemplo, o atendimento jurídico às comunidades carentes, garantindo a elas acesso à justiça e resoluções de pequenos conflitos por meio da implantação das clinicas jurídicas comunitárias.

Lado outro, por mais distintas as argumentações dos autores em debate, todos aqui apresentados identificam que um dos motivos da grande massa de bacharéis em Direito estar trabalhando fora de sua atuação profissional ou não logrando êxito na aprovação do processo avaliativo da $\mathrm{OAB}$ se dá por alguma falha na formação educacional e seus processos de avaliação.

É considerando os dilemas apresentados até aqui que se defende a relevância do debate. A investigação a respeito de como o bacharel em Direito pode contribuir na sociedade, sem precisar passar pelo processo avaliativo da $\mathrm{OAB}$, criando políticas para profissionalizar este sujeito como acontece nos exterior, pode promover mudanças significativas no desenvolvimento local de comunidades.

Certamente, a discussão permanece aberta, e há enormes problemas, institucionais, avaliativos, de construção de políticas, a serem debatidos e atravessados. O que não se pode é ignorar são as consequências sociais e as perdas potenciais destes bacharéis, excluídos por um processo seletivo que os condena, e ao seu entorno, mesmo após investimentos pessoais, públicos e privados. Há de haver soluções, e a pretensão deste artigo e de ajudar um pouco neste sentido.

\section{REFERÊNCIAS}

ALMEIDA, Frederico; SOUZA, André L. D.; CAMARGO, Sarah B. Direito e a Realidade: Desafios Para o Ensino Jurídico. In: GHIRARD, José Garcez; FEFERBAUM, Marina. Ensino do Direito em Debate: Reflexões a partir do $1^{\circ}$ Seminário Ensino Jurídico e Formação Docente. São Paulo: Direito GV, 2013. 266 p. 
BRASIL. Decreto Lei $\mathrm{n}^{\circ}$ 8.906. de 04 de julho de 1994. Estatuto da Ordem dos Advogados do Brasil. Decretos, Brasília: Casa Civil da Presidência da República Federativa do Brasil/Subchefia para Assuntos Jurídicos, 04 jul. 1994. Disponível em: <http://www.planalto.gov.br/ccivil_03/Leis/L8906.htm>. Acesso em: 03 de mar. 2019.

BRASIL. Projeto de Lei Complementar PL 5.749/2013. Altera o artigo $3^{\mathrm{a}} \S 2^{\circ}$ da Lei 8.906, de 04 de julho de 1994, dispondo sobre a criação da figura do paralegal. Projeto de lei, Brasília: Câmara dos Deputados Federais, 2013.2 Disponível em: <https://www.camara.leg.br/proposicoesWeb/prop_mostrarintegra;jsessionid=09DBE29F100B9 A1B2394F3AD4FE8168D.node2?codteor=1103459efilename=Avulso+-PL+5749/2013 >.

Acesso em: 03 de mar. 2019.

BRASIL. Instituições de Educação Superior e Cursos cadastrados. Brasília: MEC Ministério de Educação e Cultura, 2016. Disponível em: <http://emec.mec.gov.br/>. Acesso em: 20 de out. 2016.

BRITTAIN, Vicki; HULL, Terry. Paralegal Handbook. New York: Thomson/Delmar Learning, 2003. 448 p.

COWLEY, Jill I. A comparative study of paralegalism in Australia, the United States of America and England and Wales. 2004. 233f. Masters thesis. Southern Cross University. New South Wales, 2004.

ESTEBAN, Maria T.. Encontros e desencontros no cotidiano escolar. Revista Teias. V. 14, n. 33, p. 168-175, 2013. Disponível em: <http://www.epublicacoes.uerj.br/index.php/revistateias/article/view/24371/17349 >. Acesso em: 16 de jan. 2018 .

FREIRE, Paulo. Pedagogia do Oprimido. Rio de Janeiro: Paz e Terra, 1987. 253 p.

GASPAR, Alberto. A educação formal e a educação informal em ciências. In: MASSARANI, Luísa; MOREIRA, Ildeu C.; BRITO, Fátima. Ciência e Público: caminhos da divulgação científica no Brasil. Rio de Janeiro: Casa da Ciência - Centro Cultural de Ciência e Tecnologia da Universidade Federal do Rio de Janeiro, 2002. 231 p.

COSTA, Rodrigo H. Notas sobre a Educação formal, não formal e informal. Anais do III SIMPOM 2014 - Simpósio brasileiro de pós-graduandos em música. Rio de Janeiro. 2014. Disponível em: <http://www.seer.unirio.br/index.php/simpom/article/viewFile/4578/4100>. Acesso em: 03 de mar. 2019.

JAICHAND, Vinodh. Estratégias de litígio de interesse público para o avanço dos direitos humanos em sistemas domésticos de Direito. Revista Internacional de Direitos Humanos SUR. V. $\quad 1, \quad$ n. $\quad 1, \quad$ p. $\quad 1, \quad 2004$ Disponível $<$ http://www.conectas.org/pt/acoes/sur/edicao/1/1000220-estrategias-de-litigio-estrategico-deinteresse-publico-para-o-avanco-dos-direitos-humanos-em-sistemas-domesticos-de-direito $>$. Acesso em: 15/05/2017.

KANAYAMA, Rodrigo L.; FILHO, Ilton. N. R.; TOMIO, Fabrício R. L. Vamos debater a educação Jurídica e, por consequência, os Paralegais. Gazeta do Povo. 28 de agosto 2014. Disponível em <http://www.gazetadopovo.com.br/vida-publica/justica-direito/artigos/vamosdebater-a-educacao-juridica-e-por-consequencia-os-paralegais-ecp1jtm5fx8vzi1w0sod5uvda>. Acesso em: 06 de jul. 2017. 
KANAYMA, Rodrigo. Carreiras Jurídicas no Japão. Gazeta do Povo. 03 de setembro 2014. Disponível em <http://www.gazetadopovo.com.br/blogs/dinheiro-publico/carreiras-juridicas-nojapao/>. Acesso em: 11/05/2017.

LEISTER, Margareth A.; TREVISAM, Elisaide. A Necessidade da Transversalidade no Ensino Jurídico para uma Efetiva Contribuição do Jurista no Desenvolvimento da Sociedade: Um Olhar Segundo Reflexões de Edgar Morin. In: GHIRARD, José Garcez; FEFERBAUM, Marina. Ensino do Direito em Debate: Reflexões a partir do $1^{\circ}$ Seminário Ensino Jurídico e Formação Docente. São Paulo: Direito GV, 2013. 266 p.

MELLO, Marco A.. Recurso Extraordinário no 603.583. Brasília: Supremo Tribunal Federal. 26 de Outubro 2011. Disponível em: <http://redir.stf.jus.br/paginadorpub/paginador.jsp?docTP=TPedocID=2056975>. Acesso em: 03 de mar. 2019.

$\begin{array}{cccccc}\text { OAB - ORDEM DOS } & \text { ADVOGADOS } & \text { DO BRASIL. Desempenho por IES e Campus } \\ \text { (resultado } & \text { final). } & \text { Brasil: } & \text { OAB. } & 2016 . & \text { Disponível }\end{array}$ <http://www.oab.org.br/servicos/examedeordem>. Acesso em: 18 de out. 2016.

ZUGMAN, Daniel L.; BASTOS, Frederico S. (2013). As escolhas por trás do método: contradições, incoerências e patologias do ensino jurídico no Brasil. In: GHIRARD, José Garcez; FEFERBAUM, Marina. Ensino do Direito em Debate: Reflexões a partir do $1^{\circ}$ Seminário Ensino Jurídico e Formação Docente. São Paulo: Direito GV, 2013. 266 p. 